\title{
Ярослав Мельник
}

$$
|\mathbf{C}| \mathbf{O}|\mathbf{P}| \mathbf{E} \mid \underset{\substack{\text { Member since } \\ \text { JM14477 }}}{2019}
$$

(D) https://orcid.org/0000-0001-5511-1881

Прикарпатский национальный университет

имени Василя Стефаника

Факультет филологии

76018 , г. Ивано-Франковськ,

ул. Т. Шевченка, 57

mel.jaroslav@gmail.com

\section{Коммуникативный феномен морально-этических посылов Иисуса Христа: дискурсивно-типологический аспект}

\author{
The Communicative Phenomenon of the Moral \\ and Ethical Messages of Jesus Christ: A Discursive and Typological Aspect
}

\begin{abstract}
Резюме
В статье рассматривается специфика формообразования дискурсивно-информационного пространства в этнокультуре древних иудеев в контексте учений Иисуса Христа. Ключевой моделью коммуникативного поведения Мессии был посыл. Посыл же рассматривается как новая термино-понятийная категория современной дискурсологии и коммуникативной лингвистики. В контексте коммуникативной концепции Сына Божьего следует воспринимать как базисную модель, которая отличается от поучений, нравоучений, наставлений, морализации, пророческого императива и т.п. Предложенная интерпретация представляет собой несколько иной тип разворачивания идеи, ее композиционно-тематическое оформление. В основе коммуникативно-информационного посыла в текстах Нового Завета лежит морально-этическая конструкт-платформа, главная цель которой состоит в изменении культурно-духовных констант и стереотипов и направлении мира человека в благоразумное и богоугодное русло. Это является главной миссией Иисуса Христа как Сына Божьего - законодателя устройства Вселенной и человеческой цивилизации.
\end{abstract}

Ключевые слова: коммуникация, стереотип, посыл, текст, обращение, морально-этический комплекс.

\section{Summary}

The article discusses the particulars of the shaping of the discursive and informational space in the ethnic culture of ancient Jews in the context of the teachings of Jesus Christ. The key model of the Messiah's communicative behavior was the message. The message is considered a new term 
and conceptual category of modern discourse and communicative linguistics. In the context of the communicative concept of the Son of God, it should be understood as a basic model that differs from teachings, moralizations, instructions, a prophetic imperative, etc. The proposed interpretation is a subtly different type of development of the idea, its composition and thematic design. The communication and information message in the texts of the New Testament is based on a moral and ethical construct platform, the main purpose of which is to change cultural and spiritual constants and stereotypes and to steer the human world to follow a judicious and pious course. This is the main mission of Jesus Christ as the Son of God: the legislator of the structure of the universe and human civilization.

Keywords: communication, stereotype, message, text, appeal, moral and ethical complex.

\section{ВВЕДЕНИЕ}

В лингвистике последних десятилетий произошел настоящий прорыв, в результате которого учения о языке вышли на новый уровень. Это стало возможным благодаря научным разработкам, которые были заложены в свое время В. фон Гумбольдтом. Идеи выдающегося немецкого ученого получили новый импульс в трудах Ф. де Соссюра, Сепира-Уорфа, Ю. Степанова, А. Вежбицкой и многих других исследователей. Новое панорамное «разворачивание» учений о слове произошло в 80-90-е годы прошлого века, когда в научно-терминологическом континууме плотно утвердились такие категории, как языковая картина мира, концепт, стереотип, культурная константа, фрейм, гештальт, архетип и пр. (Вежбиньски, 2015, 165). Кроме этих категорий, в научный обиход вошло много новых понятий, в частности, экология языка, экология культуры, духовное пространство языка, ментальный тип и пр. Также очертилась парадигма целых направлений филологии - это неориторика, нарратология, культурно-языковая генеалогия и др. (Степанов, $1995,7)$. В контексте этих новшеств и трансформаций по-новому зазвучали давно разрабатываемые проблемы и по-особому высвечивается эпоха неоструктурализма, информационной глобализации и цифровых технологий (Деррида, 2007, 13).

\section{ОСНОВНОЙ ВОПРОС}

Сужая тему, обратимся к парадигме и идейным реформациям в области коммуникации, текстообразования, неориторики и дискурсологии. Поскольку эти направления достаточно новы, то, естественно, и терминологи- 
ческий аппарат переживает свое становление, определяется семантическая структура и функциональные особенности каждой из категорий (Мельник, 2015-2016, 205). В этом ключе следует обратить внимание на такое термино-понятийное образование, как посыл (Мельник, 2019, 53). Эта категория употребляется в сценическом искусстве, а также изредка в публичных выступлениях, обращениях к массовой аудитории и т. п., но чаще всего эта лексема и ее внутренняя форма манифестирует разговорный жанр. Она является своеобразной метафорой, аллюзией обозначения принципа организации текстового и околотекстового пространства - в современной науке чаще - дискурса (Мельник, 2019, 53-54).

Главное отличие посыла от обращения, апелляции, адресации, волеизъявления, императива и пр. категорий заключается в том, что nосыл - это более масштабный, упорядоченный, внутренне организованный и сфокусированный, подчиненный закону наибольшего коэффициента полезного действия, ожидание максимального результата, это влияние, воздействие и максимально широкая и объективная интерпретация в масштабе глобального позиционирования, в формате, выходящем за рамки реального пространства и времени, т. е. с претензией на всеобщность. Посыл - это трансформация говорящего, его внутренней духовной энергии в конкретную точку и с обязательным высокоточным попаданием. Посыл - это организующий принцип и закон. Он соотносим с риторическим идеалом (Ворожбитова, 2018, 8). Ему подчиняется как каждый текстово-вербальный сегмент (импульс), текст как цельное образование, так и весь нетекстовый (в том числе и паралингвистический) комплекс. «Посыл всегда прагматичен и наполнен высокой концентрацией духовной энергии» (Мельник, 2019, 53). В нем кодируются микро- и макропрограммы. Его целью всегда есть стремление «достучаться» до адресата, получить отражение, реакцию. Посыл должен быть принят, услышан. В противном случае он превращается в обращение, которое с легкостью отстраняет или отклоняет адресат. Посыл всегда перформативен. Это всегда слово-действие, слово-поступок, слово-оценка, попытка «перезагрузки», слово-эмоция. Посыл всегда содержит мировоззренческо-этнокультурный, социокультурный, аксиологический, философско-эстетический компоненты. Посыл - это своеобразный крик-обращение (тут можно вспомнить известное полотно Э. Мунка), которое не бывает случайным, развлекательным или шуточным. Необходимость изменить мир, внести принципиальные коррективы в его композицию. Это предупреждение и призыв расширить угол зрения и навести фокус взгляда на вещи более важные и не распыляться, не отвлекаться на второстепенные детали. В посыле всегда содержится геном-программа - поиск истины; и субъективное понимание добра и зла. Правда, иногда это может быть узкоформатным пониманием, в других случаях это истины божественного или вселенского уровня. Посыл - это предостережение и просьба понять, в чем суть истины. В посыле всегда заложены 
каноны миропонимания говорящего. Это попытка постижения экзистенции и сенсорной депревации - выход за пределы собственного «я». Это намерение трансформировать свой опыт миропостижения во всеобщий опыт познания действительности. В посыле в сложной композитной форме сливаются осознанное и подсознательное, реальное и экзистенциальное. Посыл - это не легкий эскиз-набросок, а попытка что-то сказать. Это всегда жестко организованная физическая, духовная и словесная материя. В посыле главную функцию всегда выполняет слово. Оно перестает быть лексической единицей или единицей речи. Слову, подобно лазерному лучу, предназначено пробить брешь всеобщего непонимания. Речь, организованная в посыл, подчиняется концепции поиска оптимальных форм решения проблемы. Намерение «достучаться» до ума, сердца, сознания. Посыл обладает собственной эстетикой. Это форма, стиль, жанр. В них же компоненты приобретают единое векторное направление, их суммарная величина должна обрести материально-сценарийное воплощение, результат. В посыле говорящий превращается в текст и становится текстом. Посыл всегда интертекстуален и глубоко семиотичен (Вежбиньски, 2008, 179). Глубина его прагматико-семиотической структуры неисчерпаема, и после достижения каждого уровня его понимания и рецепции обнаруживается новая перспектива. В связи с этим далеко не все тексты подпадают под категорию посыла. Удельный вес посыла всегда максимален. Он не бывает легким и не обладает бижутерными свойствами. Это не шоу. Тексты посыла всегда глубоки и обладают широким спектром интерпретаций. Их можно воспринимать с наивным простодушием, примитивно, но постижение глубин всегда сложно и требует значительных духовных усилий со стороны рецептора (Гадамер, 1991, 18). Посыл - это движение от грубого и деструктивного к гармоничному и совершенному. История человечества может быть прочитана и в контексте формирования текстовых посылов. Посыль - это всегда эмпатия и откровение. Главные тексты-посылы создавались в разные эпохи, и самые важные написаны гусиным пером на пергаменте или папирусе. В отдельных случаях высечены на камне или трансформировались в художественные (живописные) образы. Такими посылами являются также объекты архитектуры. Тексты-посылы всегда мегалитичны и несут в себе всеобщие принципы. Читабельность посылов усложняется глубоким иносказанием. Они наполняются сложной многоуровневой метафорой, неожиданными эпитетами и сравнениями. В одних случаях они обладают криптоподтекстом, в них закодированы скрытые смыслы, требующие дешифровки, в других - источник посыла, автор текста выводит на поверхность и «одевает» в сюжет, на первый взгляд, бытовые и простые формы, создает доступные образы, упрощает конфликт. Но делается это исключительно с целью быть доступным, понятным, принятым. Посылы чаще всего неориторичны - в них преобладает интерпретация (Ерушевич, 2002, 3-4). Убеждение - главный инструмент классической риторики - отодвигается 
на задний план. Убеждение ненадежно и примитивно. Только глубокое проникновение в суть проблемы и понимание явлений на уровне смысловых монад, идейных субстанций дает шанс докопаться до истины. Поэтому мы в сакральных текстах, притчах часто обнаруживаем, на первый взгляд, простые сюжеты, но со временем открываем глубину теста по принципу герменевтического круга. Как мы уже заметили, посылы - это не «легкое чтиво». Это всегда тяжелый труд, сотрудничество с источником текста - будь то Бог, пророк, философ, мыслитель или поэт. Посыль - это путь к прозрению. Они отчасти драматичны. И, очевидно, не каждый человек может пройти непростой стезей прозрения под влиянием глубоких текстов. Но каждый на своем уровне может хотя бы частично приобщиться к великому текстовому наследию. Ошибочно утверждать, что только сакральные тексты обладают качеством посылов. Такой природой наделены тексты классиков мировой литературы и философской мысли. И тут стоит следующая проблема - проблема «узнавания» и правильного прочтения - поиск верной герменевтической формулы. В контексте сказанного обратимся к текстовым посылам Нового Завета и попытаемся увидеть семантико-семиотические доминанты, ключевые формулы программирования человеческой действительности и определение аксиологических ориентиров (Вежбицкая, 1999, 682). «В них подсказка - эволюция физическая без эволюции духовной приведет к непременным катастрофам апокалиптического масштаба» (Мельник, 2012, 4).

Итак, главной идеей настоящего изыскания является то, что в эпоху Иисуса Христа, равно как до и после Его, мир был переполнен всевозможными пороками. Воровство, грабеж, обман, убийства, разного характера мошенничество, шулерство, насилие и пр. сопровождали всю историю человечества. Этими же пороками обозначена эпоха Иисуса. Но в сюжете Евангелия (и близких к нему текстов) мы обнаруживаем интересную закономерность -

Христос почти все свои посылы, истории, притчи, обращения ориентирует на книжников, первосвященников, фарисеев, лицемеров, лживых пророков, мытарей, грешников, завистников. В этих категориях сознания, ментального пространства, коммуникативных сценариев, социокультурных стереотипов, мыслительно-поведенческих традиций Христос находит наивысшее зло (Melnyk, 2019, 119).

Быть завистливым, имитативно преданным и верным учениям; фальшивым, красивыми словами прикрывать подлые замыслы; публично демонстрировать набожность и приверженность религиозным традициям, внешне живя по законам Старого Завета (законам Моисея); изощряться в издевательстве над соплеменниками - не гнушаться настоящих грабежей, собирая дань для поработителей - в данной ситуации для Римской империи, чем занимались мытари (собиратели податей); одновременно служить многим богам; быть циничным эгоистом, не любить Бога и не уважать отца; игнорировать законы, ниспосланные Всевышним, и, наконец, жить по законам, 
но игнорируя любовь (т. е. не любя), с точки зрения Христа есть более (по крайней мере - не менее) греховным, чем грабя и убивая. Поэтому в фокусе коммуникативных посылов Иисуса мы редко обнаруживаем персонажей, которые в наши дни были бы опекаемы уголовным кодексом, а видим элиту общества, духовных предводителей, законодателей и законоучителей, служителей государственной системы и прочих действующих лиц, которые в то время, равно как и в наше, имеют довольно приличный социальный статус. Именно их Христос призывает покаяться, очистить душу и встать на путь истинный. Вселенское зло и порождения лукавого содержатся в душевных пороках, а они, в свою очередь, трансформируются в мысли и слова.

Текст Священного Писания сориентирован и целенаправлен главным образом на конгломерат человеческих пороков, которые наполняют сознание, картину мира, ментальное пространство всего общества - от бездомных и нищих до власть имущих - царей, императоров, духовных лидеров. Коммуникативные программы, посылы Иисуса Христа нацелены именно на эти грехи и изъяны. И, как мы уже заметили, самым распространенным средством и средой существования этих пороков является логосфера - пространство мысли и слова. Т. е. наибольшая, все разрушающая концентрация зла содержится именно в логосферическом поле. Там необходимо искать корень зла и осуществлять основные манипуляции. Это значит - следует лечить логосферическое пространство и человека как носителя и отражателя-репрезентанта этого пространства. Слово и мысль - это неделимая бинарная субстанция, очень тонкая материя, в которой допустимо неисчислимое количество интерпретаций, видений, пониманий и высказываний по поводу любого факта бытия. Именно в файлах логосферического пространства проще всего спрятать злые замыслы и собственную порочность. При этом театр жизни предполагает игру - создание нужного образа. Т. е. жадный может сыграть щедрого, глупый - умного, лживый - искреннего, грешник - праведного. При этом словесная декорация в полной мере используется для отвлечения внимания, обмана и откровенной лжи. Имитативная приверженность законам, правилам, нормам и морали социальной среды предполагает «игру на публику» - манифестацию собственной правильности, законопослушания и приверженности высшим общественным идеалам. Но настоящая беда, боль и трагедия Иисуса, равно как и всего человечества, в том, что такие театральные постановки, инсценизации обрели канонический статус. Стали обязательной нормой жизни. И это не этикетные рамки коммуникации, а своеобразная форма культуры: думать одно - говорить совсем другое; говорить, обещать, клясться в одном, а делать нечто совершенно противоположное. При этом всегда оставаться «на плаву», манипулируя такими понятиями, как заблуждение, ошибка, точка зрения, специфика видения или миропонимания, личное убеждение, неполное понимание происходящего, я вынужден действовать в рамках закона, не я придумал эти правила и т. д. 
для отступления в случае просчета и очевидного провала. Все лживые, неискренние, лукавые оппоненты Христа формируют единый оппозиционный блок. Сын Божий указывает на поляризацию мира людей, где в непримиримой оппозиции находятся добро и зло. При этом у человека всегда есть возможность выбора, шанс покаяться. Посылы Нового Завета и Иисуса Христа в частности проектируются на реальный мир, и в контрастивном аспекте Мессия помогает отличить одно от другого - узнать то и другое. Все посылы Иисуса - это своеобразные дискурсивные срезы, в которых высвечивается текстура времени подобно годовым кольцам дерева, открывается внутренняя структура. Она не видна при поверхностном обозрении. Анатомизация дискурса (в контексте посылов) является ценным ключом к пониманию эпохи древних иудеев и всех предыдущих и последующих эпох. «Моральный формализм», внешнее, имитативное следование букве закона - одно из многих зол. У этого зла огромный адаптативный потенциал. Христос обращается к элите своего времени - книжникам и фарисеям: «Порождения ехидны! Как вы можете говорить доброе, будучи злы? Ибо от избытка сердца говорят уста. Добрый человек из доброго сокровища выносит доброе, а злой человек из злого сокровища выносит злое» (Мтф. 12, 34-35). Христос постоянно упрекает в пустословии, демагогии, популизме и неоправданной витиеватости слов. Все это является греховным вдвойне, когда под внешним словесным лоском скрыты цинизм, зависть, немилость: «Говорю же вам, что за всякое праздное слово, которое скажут люди, дадут они ответ в день суда: ибо от слов своих оправдываешься и от слов своих осудишься» (Мтф. 12, 36-37).

В словообилии Христос тоже видит грех. В словах может раствориться истина, легко потерять нить правды. В молчаливом созерцании больше истины, чем в словесных излияниях Иисус сказал: неужели и вы еще не разумеете, что все входящее в уста проходит в чрево и извергается вон? А исходящее из уст - из сердца исходит - сие оскверняет человека, ибо из сердца исходят злые помыслы, убийства, прелюбодеяния, любодеяния, кражи, лжесвидетельства, хуления - это оскверняет человека... (Мтф. 15, 16-19).

Христос призывает неуклонно оберегаться «науки фарисейской», ибо, слушая фарисеев, человек не в состоянии разобраться, где истина, а где обман. А также он призывает судить о человеке «не по словам его, а по делам его». Ибо слово в устах фарисеев и лицемеров всегда яркая и красивая накидка, под которой скрывается зло: «На Моисеевом седалище сели книжники и фарисеи; итак все, что они велят вам соблюдать, соблюдайте и делайте; по делам же их не поступайте, ибо они говорят и не делают...» (Мтф. 23, 3-4).

В устах лицемера и фарисея лживо все. Даже обращение к Богу не обозначено искренностью и откровением - молитва лжива: «Горе вам, книжники и фарисеи, лицемеры, что поедаете домы вдов и лицемерно долго молитесь...» (Мтф. 23, 14). 
Язык, речь, слово - это та ткань, в которую вплетается греховная ложь, и фактурно она не прочитывается. Нужна особая осторожность - работа души, чтобы не впустить в свою реальность лжеучения первосвященников и фарисеев. За их словами всегда прячутся скрытые помыслы, коварство, изощренно злые стремления. К злым началам принадлежат не только упомянутые выше формы коммуникативного поведения, но и лихоимство, коварство, гордыня, карьеризм, чревоугодие, восхищение собственным величием и социальным статусом, желание властвовать и многие другие. На фоне лжи, сребролюбия и многих прочих грехов перечисленные выше являются не меньшим злом, ибо тесно переплетаются с другими видами греха и выстраивают целую систему плотно связанных пороков. В своих коммуникативных спаррингах, посылах Христос часто пользуется лаконичными, но необыкновенно емкими фразами, в которых закодированы опыт борьбы добра и зла, воля Всевышнего. В этих голографических образцах свернута сложная генетическая структура - смысловой набор, который требует разъяснений. Поэтому Учитель часто прибегает к небольшим «разворачиваниям текста» в форме комментариев, параллелизма, аналогий или притч. Но его слово всегда взвешено, идеально точно и звучит не просто убедительно, а как филигранно точная и незаменимая деталь. Поэтому тексты, посылы, слова в устах Иисуса всегда точны и действенны. Они не убедительны - убеждения зачастую бывают витиевато-лживыми; они доказательны и безупречны с точки зрения логики. Более того, Христос всегда оставляет за оппонентом возможность и право не соглашаться, остаться на своих позициях.

Ментально-коммуникативное поведение фарисеев, книжников и лицемеров соответствует стереотипам и дискурсу эпохи Иисуса. Эта кавалькада ментальных клише и культурных констант выходит за рамки семантики и становится глубоко семиотичной, переходит в разряд устойчивых мифологем. Поэтому Христос с учениками оказался на поле битвы, и перед ним оказалась целая система. А каждая система, как известно, тогда является системой, когда она обладает механизмами самозащиты и самосохранения. Воевать с системой всегда сложнее, чем с отдельными его проявлениями. Поэтому мы встречаем зачастую факты (в тексте Евангелия), когда к Христу подошли первосвященники, книжники и фарисеи, т. е. они единым фронтом, целостной оппозицией восстают против Христа. Поэтому Иисус обращается как к единообразной среде, а они, в свою очередь, обращаются к Учителю и окружающим тоже единым текстом, т. е. говорят на одном языке - языке лицемерия, лжепророчества. Христос с горечью указывает на то, что молитвы, клятвы, обещания, исповедь, предостережения, утверждения, проповеди, просьбы и пр. тоже не чисты. Они не искренние. Иисус при этом не пользуется терминопонятием полуправда, но очень часто указывает на то, что измененный и искаженный факт, осознанно деформированная и искаженная информация с хорошо отслеживаемой прагматикой тоже греховна. Более 
того, она опаснее лжи, поскольку сложно узнаваема. В связи с этим Иисус всегда называет вещи своими именами - разводит здоровое зерно и мякину, не разрешает смешивать праведное с грешным.

Лицемер в древней культуре и дискурсе - это актер, игрок, лищедей, тот, кто играет другого, не является самим собой. Сценарий поведения лицемера всегда многообразен. Он умеет «ускользать» от неудобных ответов, не отвечать прямо. Диаметрально противоположная модель коммуникативного поведения Христа, когда каждый сегмент его коммуникативного посыла проверен на чистоту и высокопробность. Христу невозможно возражать, его невозможно переубедить. Его устами глаголит истина, поэтому фарисеи и лицемеры, чувствуя свою слабость, прибегают к еще более изысканным хитростям, соблазнам, угрозам, попыткам поставить «коммуникативную подножку». И в финальном этапе именно они пришли толпой к Понтию Пилату с требованием отпустить Варавву (убийцу, преступника), а распять именно Христа. С точки зрения первосвященников, фарисеев и лицемеров, убийца не так опасен для общества. В нем не видят социальной угрозы (Мтф. 27, 20-26). Опасность истекает именно от Иисуса, поскольку он призывает жить по закону Божьему, правды и добра (Ин. 19, 6-8; 15). В этом контексте даже Иуда - предатель и изменник - выглядит благородно, ибо он, чувствуя угрызения совести, перенося душевное терзание содеянным, покончил с собой, а не построил себе виллу или нечто подобное. Он тоже своеобразная жертва. На его судьбу, очевидно, повлияли посылы Христа (Мтф. 27, 3-5).

Словесный фальсификат не просто искажает и деформирует дискурс, он вносит концептуальную деструкцию в основные каноны миростроения. Природа, мир, Вселенная совершенны. Несовершенен мир человека. Его базисный изъян - это ложь, лицемерие, лживость, зависть и пр. модели поведения, которые свойственны человеческому обществу. И, как было замечено выше, человек виртуозно прячет свой негатив в слова, тексты. Обращения к Иисусу со стороны его оппозиционеров не являются посылом. Это всего лишь изысканные пируэты слов, нагромождение фальшивых аргументов. С точки зрения теории коммуникации и предложенного материала nоcblл обладает другими свойствами. Это не словесная эквилибристика, а поток интеллектуально-коммуникативной энергии. Информационная насыщенность посыла всегда несоразмерна с обращениями, апелляциями, адресациями и пр. Коммуникативно-смысловые изобретения лжепророков и лицемерных первосвященников, которые выстраивают свои оборонительные позиции перед посылами Иисуса, внешне выглядят убедительно, но всегда обречены на провал. Посылы Христа, даже если это короткие притчи, обладают смысловым совершенством. Одной даже короткой репликой он в состоянии разрушить целое фортификационное сооружение оппонентов. И, что важно, когда к Христу подходит толпа древнеиудейских интеллектуалов (учителей 
закона Божьего, священнослужителей) с весомыми аргументами, то одна короткая фраза Сына Божьего становится тем ядром, от которого рассыпается целая крепость. Например, притча о блуднице (Ин. 8, 4-7), в которой Христос предлагает безгрешному первым бросить камень.

Мир, Вселенная - это храм Божий, и весьма символично с идеальной точностью Христос призывает и самолично изгоняет из храма торговцев. В торговле, бизнесе, когда все меряется лептой или талантом, нет места любви, искренности, истине. Торгующий человек и меняла - всегда эгоист и стремится получить наибольшую выгоду от своего бизнеса. Несовместимы мир Бога, любви и правды с миром коммерции (Мтф. 21, 12-13; Мрк. 11, 15-17; Лк. 19, 45-46; Ин. 2, 14-16). Разве что поднять уровень коммерческого сознания и культуры до уровня Господней любви. Но в тексте Священного Писания не сказано о вероятности такого варианта товарно-денежных отношений между людьми. Поэтому у Христа был только один сценарий - изгнать торговцев из храма. И эта притча-история стала очень сильной формулировкой, безупречной аллегорией, образом здорового дискурса - коммуникативного пространства, организованного по закону Божьему.

Апогеем в комплексе Христовых посылов являются Нагорная проповедь, Заповеди, молитвы. По жанру они несколько отличаются от притч, но в системе посылов занимают доминирующее место. Являются организующим ядром, вокруг которого выстраиваются информация, текст, идея. Реальный мир - мир человека - по Божьему замыслу должен выстраиваться аналогично, по этому же принципу.

\section{ВЫВОДЫ}

Текст Священного Писания в современной картине мира, равно как во все предыдущие и последующие времена, кроме прочих подходов, должен быть интерпретирован сквозь призму коммуникатологии, дискурсологии, теории информациинного пространства. Это важно было всегда, но в эпоху глобализации, формирования всеобщего и тотально доступного поля информации; в эпоху изощренной манипуляции и непримиримых противостояний в борьбе за лидерство; в эпоху экологических катастроф и деградации морально-этического пространства; в эру, когда зло достигло необыкновенного совершенства и адаптировало человека; в эпоху потери религией (в частности христианством) своих законодательных и культурообразующих функций, когда волна морально-психологической и аксиологической деградации превратилась в апокалиптическое цунами (подобно Ноевому потопу), следует обратить взгляд в сторону текстового массива прошлых эпох, в частности 
Библии, и хотя бы частично следовать посылам (инструкичям, рекомендаичиям, пророчествам, наставлениям, мольбам, просьбам, приказам, скрытым и открытылм императивам, поучениям, советам и пр.) и соответственно реорганизовать дискурсивное пространство в соответствии с программными установками, которые в доступной форме изложены в текстах Священного Писания.

\section{БИБЛИОГРАФИЯ}

Библия. Книги свящеенного писания ветхого и нового Завета (1988). Москва: Издание Московской патриархии.

Вежбиньски, Я. (2008). Семантико-культурологический аспект интертекстуальности в художественном тексте. Acta Universitatis Lodziensis. Folia Linguistica Rossica. Łódź: Wydawnictwo Uniwersytetu Łódzkiego, 4, 179-187.

Вежбиньски, Я. (2015). Семантическое пространство слова Дом в русско-польском сопоставлении (на материале словарных толкований и паремиологических изречений). Acta Universitatis Lodziensis. Folia Linguistica Rossica. Łódź: Wydawnictwo Uniwersytetu Łódzkiego, 11, 165-170.

Вежбицкая, А. (1999). Семантические универсалии и описание языков. Москва: Языки русской культуры.

Ворожбитова, А.А. (2018). Лингвориторика: основы речевого самосовериенствования. Сочи: РИЦ ФГБОУ ВО «СГУ».

Гадамер, Г.-Г. (1991). Актуальность прекрасного. Москва: Искусство.

Деррида, Ж. (2007). Письмо и различие. Москва: Академический Проект.

Єрушевич, Г., Мельник Я. (2002). Вступ до риторики. Івано-Франківськ: Гостинець.

Мельник, Я.Г. (2012). Пролегомени до украӥнського дискурсу. Івано-Франківськ: В-во Прикарпатського національного університету імені Василя Стефаника.

Мельник, Я.Г. (2015-2018). Риторика та неориторика: конфлікт методологій. Вісник Прикарпатського університету. Філологія, 44-45. Івано-Франківськ: В-во Прикарпатського національного університету, 204-2011.

Мельник, Я.Г. (2019). Адресации и посыль в раннем творчестве А. Ахматовой. Вчені записки Таврійського національного університету імені В. І. Вернадського. Серія Філологія. Соціальні комунікації, 2(14), 52-58.

Степанова, Ю. (ред.). (1995). Язык и наука концуа ХХ века. Москва: Издательский центр Российского государственного гуманитарного университета.

Melnyk, J. (2019). Communicative Acts in the Texts New Testament Gospels: Mental and Axiological, Moral and Ethical Factors. Journal of Vasyl Stefanyk Precarpathian National University, 6(2), Ivano-Frankivsk, 119-128.

\section{$* * *$}

Bibliya. Knigi svyashchennogo pisaniya vetkhogo i novogo Zaveta (1988). Moscow: Izdanie Moskovskoi patriarkhii.

Derrida, Zh. (2007). Pis'mo i razlichie. Moscow: Akademicheskii Proekt.

Gadamer, G.-G. (1991). Aktual'nost'prekrasnogo. Moscow: Iskusstvo. 
Mel'nik, Ya.G. (2019). Adresatsii i posyly v rannem tvorchestve A. Akhmatovoi. Vcheni zapysky Tavriiskoho natsionalnoho universytetu imeni V. I. Vernadskoho. Seriia Filolohiia. Sotsialni komunikatsii, 2(14), 52-58.

Melnyk, Ya.H. (2012). Prolehomeny do ukrainskoho dyskursu. Ivano-Frankivsk: V-vo Prykarpatskoho natsionalnoho universytetu imeni Vasylia Stefanyka.

Melnyk, Ya.H. (2015-2018). Rytoryka ta neorytoryka: konflikt metodolohii. Visnyk Prykarpatskoho universytetu. Filolohiia, 44-45. Ivano-Frankivsk: V-vo Prykarpatskoho natsionalnoho universytetu, 204-2011.

Melnyk, J. (2019). Communicative Acts in the Texts New Testament Gospels: Mental and Axiological, Moral and Ethical Factors. Journal of Vasyl Stefanyk Precarpathian National University, 6(2), Ivano-Frankivsk, 119-128.

Stepanova, Yu. (red.). (1995). Yazyk i nauka kontsa XX veka. Moscow: Izdatel'skii tsentr Rossiiskogo gosudarstvennogo gumanitarnogo universiteta.

Vezhbin'ski, Ya. (2008). Semantiko-kul'turologicheskiiaspektintertekstual'nosti vkhudozhestvennom tekste. Acta Universitatis Lodziensis. Folia Linguistica Rossica. Łódź: Wydawnictwo Uniwersytetu Łódzkiego, 4, 179-187.

Vezhbin'ski, Ya. (2015). Semanticheskoe prostranstvo slova Dom v russko-pol'skom sopostavlenii (na materiale slovarnykh tolkovanii i paremiologicheskikh izrechenii). Acta Universitatis Lodziensis. Folia Linguistica Rossica. Łódź: Wydawnictwo Uniwersytetu Łódzkiego, 11, $165-170$.

Vezhbitskaya, A. (1999). Semanticheskie universalii i opisanie yazykov. Moscow: Yazyki russkoi kul'tury.

Vorozhbitova, A.A. (2018). Lingvoritorika: osnovy rechevogo samosovershenstvovaniya. Sochi: RITs FGBOU VO, SGU”.

Yerushevych, H., Melnyk Ya. (2002). Vstup do rytoryky. Ivano-Frankivsk: Hostynets. 